\title{
Implant Resist Approaches for 193nm Second Generation Radiation Sensitive Developable Bottom Anti Reflective Coatings
}

\author{
Francis Houlihan, Alberto Dioses, Medhat Toukhy, Andrew Romano, Joseph \\ Oberlander, HengPeng Wu, Salem Mullen, Alexandra Krawicz, PingHung Lu, \\ and Mark Neisser
}

AZ® Electronic Materials, 70 Meister Ave, Somerville, $N J$

\begin{abstract}
Our approach towards a second generation radiation sensitive developable bottom antireflective coating (DBARC's) for $193 \mathrm{~nm}$ and its use with different implant resist resin types will be discussed. Ion beam implant resistance (As implantation $15 \mathrm{KeV}$ at $5 \times 10^{15}$ dose with $\left.20 \times 10^{-4} \mathrm{amp}\right)$ and imaging results $(1: 1 \mathrm{~L} / \mathrm{S}$ features down to $140 \mathrm{~nm})$ will be shown comparing implant resist materials based upon a fluorinated resins or alicyclic/acrylate resins. Surprisingly, we found that the non-fluorinated materials gave better implant resistance $(\sim 2-3 \times$ $10^{11}$ atoms $/ \mathrm{cm}^{2}$ ) despite the higher atomic number of fluorine compared to hydrogen in the fluorinated implant materials $\left(\sim 2-5 \times 10^{12}\right.$ atoms $\left./ \mathrm{cm}^{2}\right)$. Finally, an update on the current lithographic performance of the acrylate/alicylic implant resist on second generation DBARC will be discussed.
\end{abstract}

Keywords: 193 nm, Implant Resist, DBARC.

\section{Introduction}

Antireflective coatings (ARC) are needed in 193 $\mathrm{nm}$ lithography for image quality and critical dimension (CD) control. Bottom antireflective coatings (BARC's) have the specific process requirement that a plasma etch step is required to punch through them so that the underlying substrate (eg $\mathrm{Si}$ ) can be accessed for modification. Depending on the process, this plasma etch step may impact the quality of resist features and/or the electronic properties of the underlying substrate affecting the overall device yield. One example of such a process is ion implantation where the plasma process may disrupt the structure and electronic properties of carefully tailored layers [1]. To solve this problem there are three approaches, the use of a top ARC, Dyed Resists or a developable BARC (DBARC). A DBARC is a BARC which undergoes development in aqueous base developer and therefore does not require plasma etching for removal [2]. One example of DBARC's are constant dissolution BARC's (CDBARC's) which have a passive constant rate of dissolution. However, using DBARC's which don't just passively develop but also function as resists $[3,4]$ offers more process latitude for higher resolution applications than either the CDBARC, dye resist or top ARC approaches.

One process requirement for DBARC's is that they are insoluble in the casting solvent of the implantation resist, but soluble in the solvents used as edge bead removers (EBR's). For $193 \mathrm{~nm}$ DBARC application the material should also contain enough of a $193 \mathrm{~nm}$ chromophore to ensure that the material will function effectively as a first minimum DBARC at a thickness of $\sim 30-40 \mathrm{~nm}$. In our first generation approach, the polymer used in this DBARC is insoluble in conventional resist spincasting solvents. This material is based on a copolymer of benzyl methacrylate (BMA) and 
mevalonic lactone methacrylate (MLMA) [5]. This polymer's design was optimized to produce insoluble coatings in Propylene glycol methyl ether acetate (PGMEA) solvent, but also to ensure that it could be dissolved in 4-hydroxy- 4-methyl-2pentanone. However, intractable problems remained with this material which were as follows: It is difficult to maintain EBR compatibility after post applied bake (PAB). It is difficult to suppress undercut of the DBARC and maintain a developable image after post exposure bake (PEB) with a high activation energy $193 \mathrm{~nm}$ implant resist. Finally, bad polymerization kinetics tended to hinder high $k$ DBARC materials because of tendency for homopolymerization of MLMA when attempting to get higher proportion of benzyl methacrylate

In our second generation approach the solubility material restrictions on the DBARC are lessened by incorporating into the design a reversible crosslinking through reaction of vinyloxy materials with hydroxyl containing polymers, typically phenolic in nature [6]. Fig. 1 shows schematically the approach. In a typical process according to Fig. 1, the DBARC film just after spinning on shows EBR compatibility. However, baking the DBARC film, leads to cross linking of the DBARC film. This film then shows solvent tolerance. After resist coating and exposure, acid is generated, and during the post-exposure bake (PEB), the acid in the DBARC film breaks the cross linking, making the film soluble in tetramethylammonium (TMAH) developer.

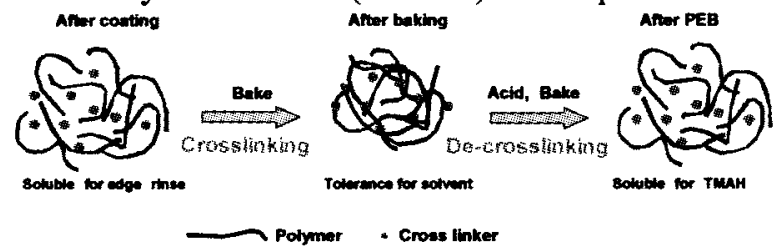

Fig. 1 Schematic Depiction of Second Generation DBARC concept.

\section{Experimental}

Typically the DBARC's the polymers used in our experiments are based on phenolic resins which are formulated with a cross-linker, a thermal acid generator and a leveling compound as described elsewhere [6] The resist formulations were either made with a fluoroalcohol based resins either obtained by modification of HFA substituted norbornene with a BOCME group (BOCME-F1) [7], a methoxymethyl protected fluorinated polymer obtained from Asahi Glass(2805 Imafukunakadai, Kawagoe, Saitama, 350-1151 Japan) (MOM-F3) (Fig. 2) or a standard acrylate/methacrylate/alicyclic type resins (Fig. 3). These materials are made by dissolving together the polymer, photo acid generator (PAG, e.g. triphenylsufonium nonaflate), a base (e.g. trioctylamine) and a leveling agent (surfactant) in a casting solvent as described elsewhere [8]. For a comparison basis $A Z \otimes D^{\mathrm{TM}}$ 7260 , a commercial $248 \mathrm{~nm}$ resist was also included in the implantation studies.

The resist solutions were filtered using PTFEfilters with $0.2 \mu \mathrm{m}$ pore diameters. Resist solutions were spin coated on the DBARC prototypes (as specified in text) coated on silicon wafers, and baked on a hot plate using a Tokyo Electron Clean Track Mark 8 or an ACT 12 track. Spin speed was adjusted such that $\sim 0.15 \mu \mathrm{m}$ resist film thickness was achieved. Film thickness was measured with a Nanometrics Nanospec 8 8000. The coated wafers were then exposed using a Nikon® Nikon 306D Illumination ID: $3(0.85 \mathrm{NA}, 2 / 3$ annular), and processed as follows: $\mathrm{PAB}=100^{\circ} \mathrm{C} / 60 \mathrm{~s}$, $\mathrm{PEB}=$ $110^{\circ} \mathrm{C} / 60 \mathrm{~s}$, Development time: $30 \mathrm{~s}$ (ACT12), $6 \%$ PSM (3182). The amine concentration of the clean room atmosphere was controlled below $5 \mathrm{ppb}$. Wafers were developed with a surfactant-free developer, $A Z \otimes \quad 300 \mathrm{MIF}$, containing $2.38 \%$ tetramethyl ammonium hydroxide (TMAH). Ion Implantation work: Thirteen 8" wafers were coated on a Mark 8 track and the film thicknesses measured using a Nanometrics Nanospec $\$ 8000$. The wafers were hard baked after coating at $110^{\circ} \mathrm{C}$ for 30 minutes. After hard baking, the wafers were sent to either Applied Materials (Applied Materials One Cabot road M/S 0021 Hudson, Mass. 01749) or Innovion (2121 Zanker Rd, San Jose, Ca 95301) for arsenic implanting at $15 \mathrm{KeV}$ at $5 \times \mathrm{e} 15$ dose with $20 \times 10-4$ amp. After implanting, the wafers were shipped to back Branchburg and the thicknesses were measured again using the Nanometrics Nanospec@ 8000. After the film thickness measurement, a 1 inch square was stripped using Kwik strip at $85^{\circ} \mathrm{C}$. After the stripping, arsenic content of three 1 inch squares was measured at Eveans Analytical (810 Kifer Sunnyvale Ca, 94086) by secondary ion mass spectroscopy (SIM). 


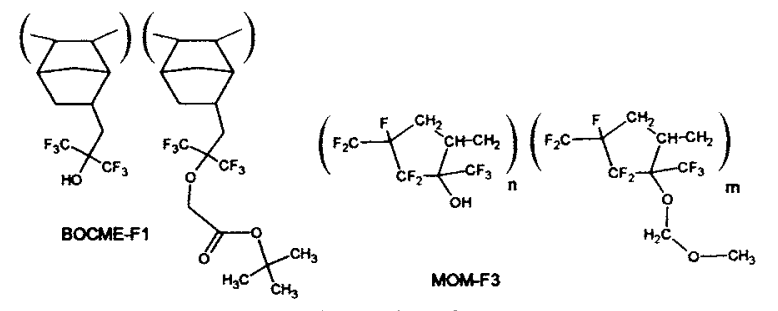

Fig. 2 Structure of fluorinated resins

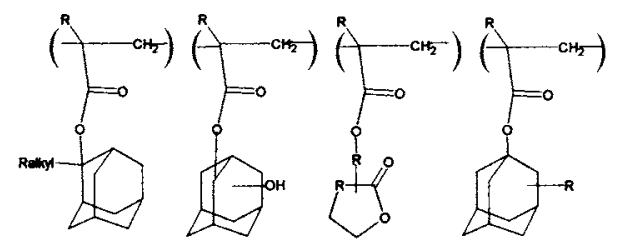

Fig. 3: Polymers structure, representative of the class of acrylate/methacrylate/alicyclic $193 \mathrm{~nm}$ resist resins.

\section{Results and Discussion}

\subsection{Background}

Fig. 4 shows a schematic depiction of how an implant resist would work together with a DBARC to mask implantation from a As Ion Beam in areas that have been delineated during the imaging step with $193 \mathrm{~nm}$. Early work on implantation through Novolak/DNQ type materials shows that a 1 micron thick film of such materials will mask all dopant ions[1] (e.g. As, B, P etc). A search of the literature on topic of As implant resistance showed some studies had been done on the effect of aliphatic versus aromatic structures [9], but no work that we could find describing how implantation might be affected by going to fluorinated polymers. On basic principles, all other things being equal, one would expect that replacing hydrogen with fluorine atoms having a much higher $\mathrm{Z}$ number should increase the stopping power of a material. Consequently, we decided to compare fluorinated alicyclic materials as implantation resists compared to more traditional acrylate/ methacrylate/alicyclic $193 \mathrm{~nm}$ materials with regards to their imaging capability, and resistance to implantation. The materials chosen for evaluation were as follows: A benchmark $248 \mathrm{~nm}$ resist (AZ®) DX $^{\text {TM }}$ 7260); several $193 \mathrm{~nm}$ non fluorinate resists (AZ@ AX ${ }^{\mathrm{TM}} 1120 \mathrm{P}, \mathrm{AZ} \otimes$ EXP 83645 and three further acrylate/methacrylate/alicyclic $193 \mathrm{~nm}$ test resist Implant Resists D, E, F) and two $193 \mathrm{~nm}$ prototype resists based on the fluorinated polymeric resins F1-BOCME and F3-MOM.

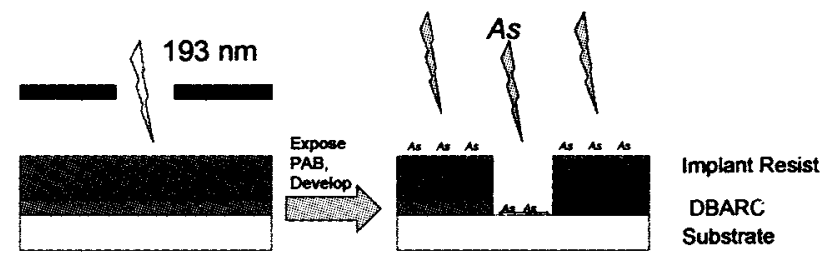

Fig. 4 Schematic Depiction the use of a DBARC with an Implant Resist to Mask Implantation from an Arsenic beam.

\subsection{Initial Imaging work}

The implant prototype resists based on fluorinated polymers had very promising lithographic behavior when screened on an early prototype of our DBARC 1 which was based upon cross-linking of a phenolic matrix with a vinyloxy compound. For instance, Fig. 5 shows some images which were obtained with a fluorinated implant resist formulated with F3-MOM. Although promising, resist based on such fluorinated material are quite expensive, and we needed to verify both that such materials had good implant resistance, and also that conventional non-fluorinated $193 \mathrm{~nm}$ systems were not suitable.

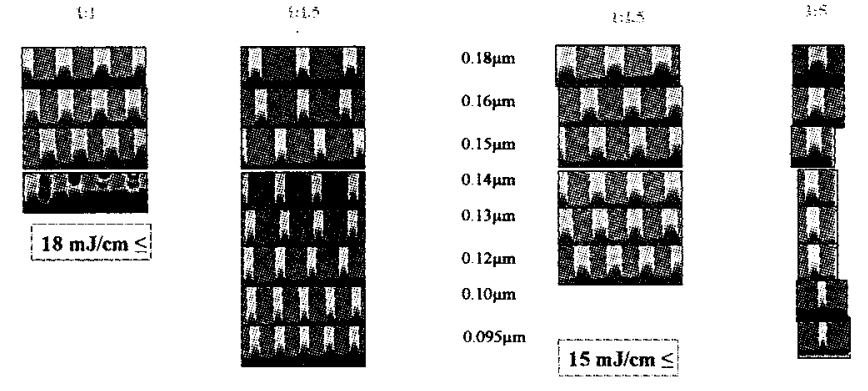

Fig. 5: Imaging of F1-MOM based Implant resist on a DBARC 3 Prototype. Process condition: DBARC coating: $\mathrm{FT}=30 \mathrm{~nm}, \mathrm{SB} 170^{\circ} \mathrm{C} / 90 \mathrm{sec}$ proximity Resist coating: $\mathrm{FT}=122 \mathrm{~nm}, \mathrm{SB} 120^{\circ} \mathrm{C} / 90 \mathrm{sec}$ proximity Exposure tool: Nikon Scanner, 0.63 NA, 0.90 sigma, $6 \%$ Att. PSM 3182 maskPEB $110^{\circ} \mathrm{C} / 90 \mathrm{sec}$ proximity, $30 \mathrm{sec}$ spray puddle in AZ 300 MIF Developer

The initial imaging work with a commercial $193 \mathrm{~nm}$ resist $\mathrm{AZB} \mathrm{AX}^{\mathrm{TM}} 1120 \mathrm{P}$ was not as promising, giving a strong tendency to undercut (Fig. 6). Fig. 6 shows a $180 \mathrm{~nm}$ trench showing severe undercutting, isolated lines and L/S features at this same feature size were lost through adhesion failure attributed to this undercut. Nonetheless, we 
proceeded to our initial implantation screening studies.

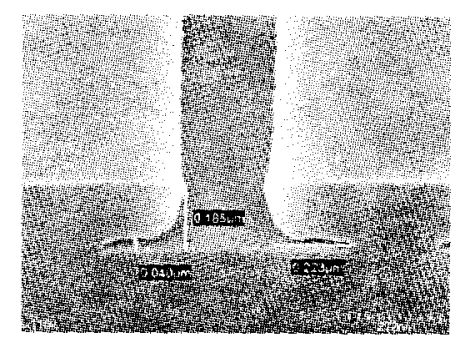

Fig. 6: Imaging of $A Z \otimes A X^{\mathrm{TM}} 1120 \mathrm{P}$ on a DBARC 1 Prototype. $18 \mathrm{~mJ} / \mathrm{cm}^{2}$ Process conditions: DBARC Process condition: DBARC coating: FT $=30 \mathrm{~nm}, \mathrm{SB}$ $180^{\circ} \mathrm{C} / 60$ sec proximity Resist coating: $\mathrm{FT}=140 \mathrm{~nm}, \mathrm{SB}$ $110^{\circ} \mathrm{C} / 60 \mathrm{sec}$ proximity Exposure tool: Nikon Scanner, $0.75 \mathrm{NA}, 0.90$ sigma, Binary Mask, PEB $110^{\circ} \mathrm{C} / 90 \mathrm{sec}$ proximity, 30sec spray puddle in AZ 300 MIF Developer

\subsection{Implantation Screening}

As detailed in the experimental section, samples of all the different types of implantation resist were coated on $\mathbf{8}$ inch silicon wafers and sent to outside vendors both for Arsenic implantation and for subsequent analysis of the extent of Arsenic implantation. Table 1 reports our initial screening results done with thick samples $(\sim 3700 \mathrm{~A})$ of a representative subset of the implant resists at our disposal. As can be seen from Table 1, both resists based on fluorinate polymers gave much worse implantation resistance, at least an order of magnitude worse than the $248 \mathrm{~nm}$ phenolic based resist AZ® DXTM 7260. Surprisingly, the $193 \mathrm{~nm}$ resist $A Z B \quad A^{\mathrm{TM}} 1120 \mathrm{P}$ gave implant resistance almost twice as good as that of the $248 \mathrm{~nm}$ reference material. This experiment was repeated for thinner samples and the results are shown in Table 2. According to Sematech, levels of implantation 1013 Atoms $/ \mathrm{cm}^{2}$ or greater is not acceptable while 1012 is acceptable. The fluorinated materials in our initial evaluation were either failing or near failure level. Our second evaluation, done for thinner films $(1700 \AA)$ at another vender, also showed that the Fluorinated materials were the worse performing. This they gave implant resistance to the As beam marginally close to failure. The conventional $193 \mathrm{~nm}$ resist systems, on the other hand, easily passed in both evaluations the Sematech acceptance criteria.
Table 1 Arsenic Stopping Power of Different Resists Film on Si

Thickness 3700 Angstroms*

\begin{tabular}{|l|l|l|}
\hline $\begin{array}{l}\text { RESIST } \\
\text { YHICKNESS) }\end{array}$ & (FILM & $\begin{array}{l}\text { Relative } \\
\text { Increase } \\
\text { in As }\end{array}$ \\
\hline BLANK & $2.60 \mathrm{E}+11$ & 1 \\
\hline BLANK+ MPLANT & $4.35 \mathrm{E}+15$ & 16,731 \\
\hline AZ@ DX'M $7260(3750 \AA)$ & $5.6 \mathrm{e}+11$ & 2.15 \\
\hline AZ@ AXTM1120P $(3750 \AA)$ & $3.55 \mathrm{E}+11$ & 1.37 \\
\hline F1-BOCME $(\sim 3700 \AA)$ & $5.00 \mathrm{E}+12$ & 19.23 \\
\hline F3-MOM $(\sim 3700 \AA)$ & $1.6 \mathrm{E}+13$ & 61.5 \\
\hline
\end{tabular}

* Initial Evaluation done at Applied Materials

Table 2 Arsenic Stopping Power of Different Resists Film

Thickness $\sim 1700$ Angstroms*

\begin{tabular}{|l|l|l|}
\hline Resist & \multicolumn{1}{|c|}{$\begin{array}{l}\text { As atoms/cm2 } \\
\text { None }\end{array}$} & $\begin{array}{l}\text { Relative Increase } \\
\text { in As }\end{array}$ \\
\hline & $6.2 \times 1015$ & 1.0 \\
\hline AZ@ AX'M1120P & $2.7 \times 1011$ & $2.3 \times 104$ \\
\hline AZ@ EXP 83645 & $3.8 \times 1011$ & $1.6 \times 104$ \\
\hline & & \\
\hline Implant Resist E & $2.6 \times 1011$ & $2.4 \times 104$ \\
\hline & & \\
Implant Resist D & $2.8 \times 1011$ & $2.2 \times 104$ \\
\hline & & \\
Implant Resist F & $3.8 \times 1011$ & $1.6 \times 104$ \\
\hline F1-BOCME & $1.6 \times 1012$ & $3.9 \times 103$ \\
\hline F3-MOM & $4.8 \times 1012$ & $1.3 \times 103$ \\
\hline
\end{tabular}

*Final evaluation done at Innovion

\subsection{Erosion During Implantation}

Table 3 shows the \% erosion during implantation. Both conventional $193 \mathrm{~nm}$ resists and resists based on fluorinated resins give reasonably low levels of erosion during the implantation process. Some of the conventional $193 \mathrm{~nm}$ resists give about twice as much erosion with the ion beam as $\mathrm{AZ} \otimes \mathrm{AX}^{\mathrm{TM}} 1120 \mathrm{P}$ or the fluoropolymer based systems. Implant resist prototypes $\mathrm{E}$ to $\mathrm{F}$ had groups attached to them more

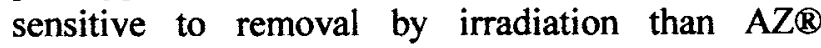


$\mathrm{AX}^{\mathrm{TM}} 1120 \mathrm{P}$, this may be responsible for their higher degree of erosion during ion implantation. As for the resists based on fluorinated materials, these have comparable erosion despite being protected with relatively low activation energy groups that could be easily cleaved. Perhaps, the higher atomic number of the fluorine atoms in these resins afforded better protection against erosion by the Arsenic Ion Beam. If true this would ironically confirm that our hypothesis that fluorinated are more resistant to the implant beam, but that unfortunately, the larger free volume of these polymers apparently overrides the sturdiness of the resin towards implantation.

Table 3 Film Erosion During Implantation and Stripping Time with Kwik strip for 1700 A thick Substrates

\begin{tabular}{|c|c|c|}
\hline Identity & $\begin{array}{l}\% \text { Erosion During } \\
\text { Implantation } \\
\end{array}$ & $\begin{array}{l}\text { Strip Time (min) } \\
85^{\circ} \mathrm{C} \text { Kwik strip }\end{array}$ \\
\hline $\mathrm{AZ} \otimes \mathrm{AX}^{\mathrm{TM}} 1120 \mathrm{P}$ & 10 & 93 \\
\hline AZ@ EXP 83645 & 16 & 23.2 \\
\hline Implant Resist E & 14 & 20.5 \\
\hline Implant Resist D & 17 & 17.3 \\
\hline Implant Resist F & 17 & 6.8 \\
\hline F3-MOM & 12 & 6.5 \\
\hline F1-BOCME & 11 & 2 \\
\hline
\end{tabular}

\subsection{Strippability of Implant resists}

Table 3 also details the strip time with Kwik strip for different samples. The strip time for most of the materials is less than 30 minutes, the fluoropolymer gives the fastest strip time, but some of conventional $193 \mathrm{~nm}$ materials are not far behind. The one exception is $\mathrm{AZ} \otimes \mathrm{AX}^{\mathrm{TM}} 1120 \mathrm{P}$ which gave a strip time of 93 minutes. This was attributed to the fact that this sample underwent some degree of charring during implantation. The greater degree of charring may perhaps be related to the fact that the $A Z \otimes A X^{\mathrm{TM}} 1120 \mathrm{P}$ sample is suffering less mass loss during implantation (i.e. lower $\%$ erosion) giving it less of a opportunity to cool during implantation by loss of small volatile fragments.

\subsection{Imaging of DBARC with acrylate/ methacrylate/alicyclic based resists}

Since the less expensive non-fluorinated $193 \mathrm{~nm}$ resist had much better implantation resistance than resists based on fluorinated resins, this warranted further work on improving the compatibility of our DBARC prototype with these resists.

As discussed previously, Fig. 6 shows our starting point when we imaged the initial DBARC

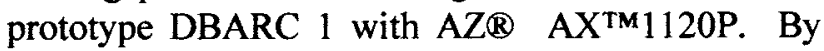
adjusting both the implant resist chemistry and DBARC chemistry through proprietary modifications of the resins and additives, we were able to better tune these two materials to be compatible with each other and to suppress the undesirable undercutting. Fig. 7 shows results that we obtained with Implant Resist D2 and an intermediate DBARC prototype DBARC3a in which the undercutting has been suppressed. This material has a tendency to form scum which is related DBARC cure temperature $180^{\circ} \mathrm{C}$ which is at the thermal stability limits of the phenolic resin.

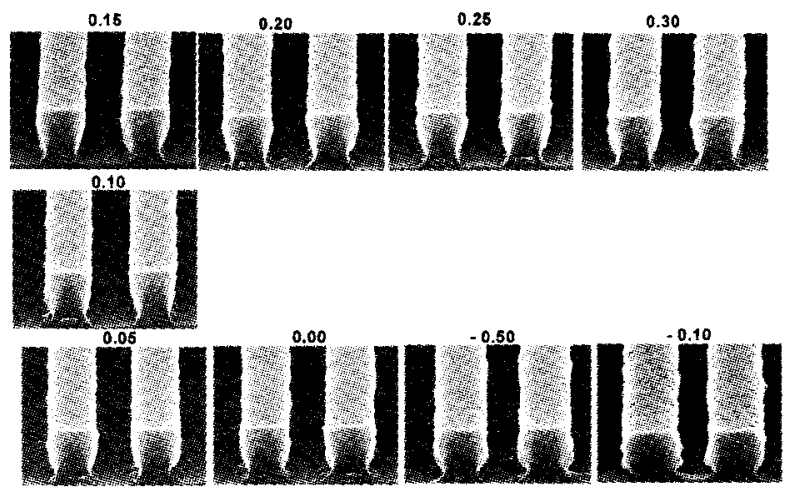

Fig. 7 Imaging of Implant Resist D2 on a DBARC3a Prototype. $18 \mathrm{~mJ} / \mathrm{cm}^{2} \quad 150 \mathrm{~nm} \quad 1: 1 \mathrm{~L} / \mathrm{S}$ Process conditions: DBARC Process condition: DBARC coating: $\mathrm{FT}=30 \mathrm{~nm}$, SB $180^{\circ} \mathrm{C} / 60 \mathrm{sec}$ proximity Resist coating: FT $=140 \mathrm{~nm}, \mathrm{SB} 110^{\circ} \mathrm{C} / 60 \mathrm{sec}$ proximity Exposure tool: Nikon Scanner, 0.75 NA, 0.90 sigma, Binary Mask, PEB $115^{\circ} \mathrm{C} / 90$ sec proximity, 30 sec spray puddle in $\mathrm{AZ} 300$ MIF Developer.

Further modification of the DBARC platform yielded protototype DBARC, DBARC6a, which allowed us to lower the PAB needed for DBARC cross-linking to temperatures as low as $110^{\circ} \mathrm{C}$. Fig. 
8 gives an example of our current imaging performance of DBARC 6a on Implant Resist D2 using a PAB temperature of only $120^{\circ} \mathrm{C}$. This material, using conventional illumination, can image $150 \mathrm{~nm} \mathrm{~L} / \mathrm{S}$ features with a depth of focus of $\sim 0.2$ and a dose latitude of about $\sim 2 \mathrm{~mJ} / \mathrm{cm}^{2}$.

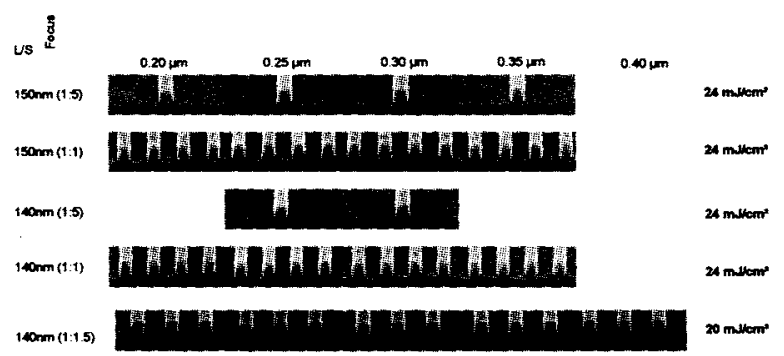

Fig. 8; DBARC 6a : FT $=40 \mathrm{~nm} / 2350 \mathrm{rpm}, \quad$ SB $120 \mathrm{C} / 60 \mathrm{sec}$

Implant Resist D2: FT $=150 \mathrm{~nm} / 1500 \mathrm{rpm}, \quad \mathrm{SB}$ $100 \mathrm{C} / 60 \mathrm{sec}$, PEB $115 \mathrm{C} / 60 \mathrm{sec}$, Dev $2.38 \%$ TMAH $21 \mathrm{C} / 30 \mathrm{sec}$

TWINSCANTM XT:1200E : NA $=0.75$, Conventional Illumination, $0.6 \mathrm{~s}$, Reticle: Binary Mask

\section{Conclusions}

Implant resists based on fluorinated materials give reasonably good lithographic performance on prototype DBARC systems based on the reversible cross-linking of phenolic matrixes. However, these fluorinated materials have poor implant resistance towards an As ion beam. Although, the higher $Z$ number of these materials may be helping to alleviate somewhat the erosion brought about by the ion beam, this effect is not sufficient to counter the high free volume of these resins which is probably what is leading to their poor performance.

However, we have shown that implant resists based on standard $193 \mathrm{~nm}$ resists based acrylate/methacrylate/alicyclic materials have much better implant resistance than the exotic fluorinated materials. The initial performance of these acrylate/ methacrylate/alicyclic materials on the prototype DBARC 1 gave a very large tendency to undercut. However, by making proprietary changes to the chemistry of the DBARC and Implant resist we were able both to suppress undercut of the DBARC while simultaneously lowering the DBARC cure temperature to $120^{\circ} \mathrm{C}$ in the promising material DBARC 6a.

\section{References}

1. "Semiconductor Lithography Principles, Practices and Materials", Wayne M Moreau, Plenum Press, New York. (1988) 620.

2. T. Hatanaka, S. Kimura, T. Eromoto and Y. Nakajima, Proc., SPIE 5376, (2004) 655-663,

3. T. Katayama, H. Motobayashi, W. Kang, M. Toukhy, J. Oberlander, S. Ding and M. Neisser, Proc., SPIE 5377, (2004) 968

4. D. Owe-Yang, B. Ho, S. Miyazaki, T. Katayama, K. Susukida, W. Kang and Y. Chang, Proc., SPIE 5376, (2004) 452

5. M. Toukhy, J. Oberlander, S. Mullen, PingHung Lu and M. Neisser Proc SPIE 2007 this conference

6. Y. Sui, H. Wu, W. Kang, M. . Neisser, T. Katayama, S. Ding-Lee, A. Hishida, J. Oberlander M. E. Toukhy US2005/0214574A1 Sept 29 (2005)

7. F. Houlihan, R.Sakamuri, D. Rentkiewicz, A. Romano, R. Dammel, M. Sebald, N. Stepanenko, C. Hohle, L. Rhodes, J. McDaniel, Chung Chang, W. Conley, G. Rich, D. Miller RETEC 2003, Tamiment Resort, USA (2003), F. Houlihan, R. Sakamuri, A. Romano, R. Dammel, W. Conley, G. Rich, D. Miller, L. Rhodes, J. McDaniels, ChunChang Proceedings of SPIE 5039, 1(2003) 64; R Dammel, , R. Sakamuri; , F. Houlihan; United States Patent Application 20050170279 Al (2004)

8. C-H Hong, S-H. Lee, W-K Kim, T. Kudo, A. Timko, D. McKenzie, C. Anyadiegwu, D. M. Rahman, G. Lin, R.R. Dammel, M. Padmanaban, Proc. SPIE 5376 (2004) 1131

9. Fujimura, Shuzo; Yano, Hiroshi; Konno, Junichi. Nuclear Instruments \& Methods in Physics Research, Section B: Beam Interactions with Materials and Atoms (1989), B39(1-4), 809-12 